This is the accepted manuscript of an article published by Taylor \& Francis in Aging and Mental Health on September 21, 2020, available online: https://doi.org/10.1080/13607863.2020.1822284

\title{
Cross-lagged relationships between sense of purpose in life, memory performance, and subjective memory beliefs in adulthood over a 9-year interval
}

Laura Dewitte, MSc, KU Leuven, ORCID: 0000-0002-8383-6801

Nathan A. Lewis, MA, University of Victoria

Brennan R. Payne, PhD, University of Utah

Nicholas A. Turiano, PhD, West Virginia University; West Virginia Prevention Research Center

Patrick L. Hill, PhD, Washington University in St. Louis

Correspondence concerning this article should be addressed to: Laura Dewitte, Faculty of Psychology and Educational Sciences, KU Leuven, Tiensestraat 102 - box 3717, Belgium. +32163742 54, laura.dewitte@kuleuven.be

\section{Funding}

This work was supported by the Research Foundation Flanders under grant 1109417N (to LD).

\section{Disclosure of Interest}

The authors report no conflict of interest. 


\begin{abstract}
Objectives: Previous studies have found a positive association between having a sense of purpose in life and memory functioning in old age. We extend these findings by examining the relationships between sense of purpose, memory performance, and subjective memory beliefs over time in a large sample of adults in mid to later adulthood.
\end{abstract}

Method: We used data from 3633 participants of the second and third wave of the MIDUS study. Cross-lagged panel analysis investigated the relationships between the variables at the two points, which were approximately 9 years apart, while controlling for gender, age, education, positive and negative affect, and self-rated health.

Results: Sense of purpose in life, memory performance, and subjective memory beliefs were all cross-sectionally related to each other at both times. Longitudinally, sense of purpose was a positive predictor of subjective memory beliefs. Memory performance and subjective memory beliefs positively predicted each other over time. Furthermore, all three variables showed correlated changes over time. Exploratory analyses suggest that the covariates of affect and self-rated health are possible mediators or confounders in respectively the relationship between subjective memory beliefs and later sense of purpose, and sense of purpose and later objective memory performance.

Conclusion: Our findings underscore once more the relevance of sense of purpose in life as a predictor of positive late life functioning, as it is related to both performance-based and subjective cognitive outcomes. More work is needed to understand mechanisms underlying the purpose-memory association in order to develop and implement purpose interventions.

Keywords: psychological well-being, cognition, aging, longitudinal 


\section{Introduction}

An increasing number of studies show associations between memory performance and having a sense of purpose in life (Boyle, Buchman, Barnes, \& Bennett, 2010; Kim, Shin, Scicolone, \& Parmelee, 2019; Lewis, Turiano, Payne, \& Hill, 2017; Wilson et al., 2013; Windsor, Curtis, \& Luszcz, 2015). These findings suggest that two key issues faced by aging adults — maintaining memory functioning and maintaining a sense of purpose in life — might be interrelated. This warrants attention because, as the proportion of older adults in the population is expanding rapidly, it is an urgent matter for aging researchers to better understand the factors related to cognitive health beyond more established correlates such as physical activity (Sofi et al., 2011), sleep (Nebes, Buysse, Halligan, Houck, \& Monk, 2009), and education (e.g., Le Carret et al., 2003). However, up to now, the longitudinal relationship between purpose in life and memory and its direction over time, is not yet firmly established. Furthermore, with the exception of some cross-sectional studies (Gates, Valenzuela, Sachdev, \& Singh, 2014; Steinberg et al., 2013), most studies have failed to take into account how subjective beliefs about memory abilities may be uniquely related to psychological outcomes, beyond objective performance.

\section{Sense of purpose and memory performance}

Sense of purpose in life can be defined as the experience of being directed in life by broad life goals, promoting the engagement in valued life activities (Ryff, 1989; Scheier et al., 2006). Empirical evidence for the importance of having a sense of purpose in life is growing steadily, with many studies now showing both cross-sectional and longitudinal relationships between sense of purpose and a range of health and well-being outcomes (e.g., Irving, Davis, \& Collier, 2017; Steptoe, 2019). In this regard, purpose in life has been put forward as a potential protective factor against cognitive decline (Boyle et al., 2010; Strout \& Howard, 2012), with possible underlying mechanisms being better health behaviors, higher stress- 
resilience, and more cognitive exercise through engagement in mentally stimulating activities (Ong \& Patterson, 2016).

However, maintaining a sense of purpose in life might not only bolster cognitive functioning, but also be contingent on it. Having a purpose in life is a complex psychological experience that can be argued to require complex cognitive skills, such as reflection on the self and the world, integration of past, present, and future, and planning and coordination of complex activities (McKnight \& Kashdan, 2009; Wilson et al., 2013). From this perspective, age-related declines in cognitive functioning might jeopardize the experience of purpose in life. Furthermore, noticing and possibly worrying about such cognitive declines might have additional negative consequences for psychological well-being, potentially amplifying the negative effect on sense of purpose (Cutler \& Brăgaru, 2016). Indeed, such a pattern would help explain findings showing that sense of purpose on average tends to decline in old age (Pinquart, 2002).

These two perspectives suggest that cognition and purpose in life might be bidirectionally related over time. However, cognition is a broad and unspecific term capturing different specific domains of cognitive functioning. One such prominent domain is, of course, memory. When people think about their own cognitive abilities and potential declines, they tend to focus predominantly on their memory functioning (Luck et al., 2018; Slavin et al., 2010). In empirical works on the relation between sense of purpose in life and cognition over time, memory performance has often been included as one of the main outcomes as well. Most of these longitudinal studies have focused on the predictive value of sense of purpose for memory, and not on the possible reversed effect of memory on sense of purpose. These studies showed that higher levels of purpose in life in older adults were related to slower decline in different memory domains (i.e., episodic, semantic, and working memory) (Boyle et al., 2010; Kim et al., 2019; Windsor et al., 2015). This association might have clinical 
relevance as well, since having a higher sense of purpose in life was related to a reduced risk of developing mild cognitive impairment and Alzheimer's disease in a 7-year study (Boyle et al., 2010), and to better cognitive performance and slower cognitive decline in those who did develop Alzheimer's disease-related damage in the brain (Boyle et al., 2012).

Although limited, there is some evidence for bi-directionality between sense of purpose in life and generalized measures of cognitive functioning, but the picture for memory functioning is unclear. In a sample of 1049 older adults with an average age of 80, sense of purpose in life and overall cognitive functioning predicted each other over time, but the crosslagged association between sense of purpose and later cognition was stronger than the crosslagged association between cognition and later sense of purpose (Wilson et al., 2013). Furthermore, initial levels of purpose in life predicted change in cognition, but initial levels of cognition did not predict change in purpose in life. When the analyses were repeated for specific domains of cognitive functioning, sense of purpose in life consistently predicted later performance in all cognitive domains assessed (episodic memory, semantic memory, working memory, perceptual speed). In the other direction, all cognitive domains except episodic memory predicted later sense of purpose in life. In a large study with 10,985 older adults between 50 and 90 years old, memory and a broad well-being measure, containing aspects related to purpose in life, did predict each other over time, though the predictive effect of memory on later well-being could be predominantly attributed to within-person fluctuations (Allerhand, Gale, \& Deary, 2014).

In sum, current evidence suggests that having a greater sense of purpose in life positively predicts cognitive functioning, and both theory and some limited research suggest that the opposite direction might also be of interest. However, a relevant construct that has not been brought into the equation is the role of subjective beliefs. Higher sense of purpose in life may not only be related to objective memory performance through practice of memory skills, 
but also to people's subjective belief in their memory abilities. Previous research has demonstrated the importance of looking at both objective cognitive performance and subjective beliefs, as they have been shown to have unique relations with, for example, personality traits (Hill, Aschwanden, Payne, \& Allemand, 2020) and future diagnosis of cognitive disorder (Mendonça, Alves, \& Bugalho, 2016).

\section{Subjective memory beliefs}

Subjective memory beliefs is the overarching term used to describe a person's beliefs about the effectiveness of their own memory functioning (Payne et al., 2017, p. 346). Within the literature, subjective memory beliefs have been assessed in different ways, reflecting different facets of the concept: from a problem-oriented view as subjective memory complaints as well as from a capacity-oriented view as general memory ability or taskspecific memory self-efficacy (Beaudoin \& Desrichard, 2011; Crumley, Stetler, \& Horhota, 2014). Taken together, the overall association between objective memory performance and subjective memory beliefs seems to be rather small, with recent effect size estimates between $r=.06$ and .10 for memory complaints (Burmester, Leathem, \& Merrick, 2016; Crumley et al., 2014), and around $r=.15$ for memory self-efficacy (Beaudoin \& Desrichard, 2011). Recent evidence suggests that subjective memory beliefs might actually correspond better to broad cognitive functioning in general than to specific memory functioning (Payne et al., 2017). Notwithstanding the modest associations between subjective and objective memory, however, there is some evidence that the relation holds over time. In a large longitudinal study of older adults, not only level but also change in subjective memory (measured generally as “How would you rate your memory at the present time?") and objective memory performance over time were positively related to each other (Hülür, Hertzog, Pearman, \& Gerstorf, 2015). A cross-lagged study focusing on subjective memory complaints showed similar results, with subjective memory complaints and objective memory performance negatively predicting each 
other over time (Jorm, Christensen, Korten, Jacomb, \& Henderson, 2001). A third large study with older adults living in the community also showed evidence for a bi-directional relationship between objective memory and subjective memory complaints over time (Snitz et al., 2015). However, one of the pathways was counter to prior work: lower scores on objective memory performance predicted more decline in subjective memory complaints. The authors suggested this finding might reflect a growing lack of insight into memory functioning when it becomes more impaired. Finally, the relevance of the relationship between subjective and objective memory over time was shown in a systematic review that concluded that subjective cognitive complaints could be an early predictor of non-normative declines in cognition, especially for those reporting repercussions in daily activities (Mendonça et al., 2016).

In sum, available evidence suggest that objective and subjective memory reports are related but not interchangeable. Adding to this idea are findings showing that subjective memory beliefs are strongly related to psychological factors. Up to now, the strongest associations have been found with respect to depressive symptoms, but associations between subjective memory and anxiety and neuroticism have also been found repeatedly (Buckley et al., 2013; Hülür et al., 2015; Hurt, Burns, \& Barrowclough, 2011; Rowell, Green, Teachman, $\&$ Salthouse, 2016). This shows that factors beyond objective test performance play an important role in how individuals experience and assess their day to day memory functioning.

Most studies have focused predominantly on how such adverse psychological variables negatively predict memory beliefs. It is surprising, however, to see a lack of studies looking into positive psychological variables. As an exception, one study found that both level and change of positive affect were negatively predictive of subjective memory complaints over time (Lee, 2016). However, this study did not control for subjective memory complaints at baseline. A recent cross-lagged study—which assessed subjective memory with items referring to both problems and overall ability — failed to find associations between subjective 
well-being (measured as life satisfaction, happiness, and life enjoyment), and objective and subjective memory (Nyström, Sörman, Kormi-Nouri, \& Rönnlund, 2019).

In this regard, sense of purpose in life might be an especially interesting concept to consider. First, the link between sense of purpose and memory performance is founded on more theoretical and empirical backing, relative to general well-being. Second, for subjective memory beliefs as well, sense of purpose in life could be expected to be more relevant, given its associations with greater efficacy beliefs, agency, and hope (Cotton Bronk, Hill, Lapsley, Talib, \& Finch, 2009; DeWitz, Woolsey, \& Walsh, 2009). In the opposite direction as well, subjectively perceiving declines in one's memory might be followed by declines in psychological well-being, leading people to report lower sense of purpose in life. A limited number of cross-sectional studies give some preliminary indication, showing positive associations between objective and subjective indicators of cognition and measures related to sense of purpose (overall psychological well-being, Gates et al., 2014; goals, Steinberg et al., 2013).

\section{Present study}

The limited number of longitudinal investigations on purpose in life and memory performance are not conclusive and have often failed to take into account that subjective memory beliefs may also be an important correlate of sense of purpose, beyond objective memory performance. In the present study, we aim to test the relations between sense of purpose in life, objective memory performance, and subjective memory beliefs over time in a large sample of adults with a wide age range, starting in middle adulthood, as normal agerelated cognitive decline can be observed to begin as early as the 30's (Salthouse, 2006). Prior to data-analysis, the study and hypotheses were registered on the Open Science Framework (https://osf.io/p57cq). We hypothesized that sense of purpose in life, subjective memory 
beliefs, and objective memory performance would be positively associated with each other at both time points, and that the three variables would positively predict each other over time.

\section{Methods}

\section{Participants}

We used data from the second and third wave of the Midlife Development in the United States (MIDUS) longitudinal study on health and well-being (Brim, Ryff, \& Kessler, 2004), as these waves contained the measures necessary for the current investigation. The second measurement wave (MIDUS2, $N=4955$ ) was conducted between 2004 and 2009 (see Radler \& Ryff, 2010 for a detailed sample description). The third measurement wave (MIDUS3, $N=3294$ ) started in 2013, and was conducted on average 9.12 years later than MIDUS 2 (Hughes, Agrigoroaei, Jeon, Bruzzese, \& Lachman, 2018). Previous work has shown a cross-sectional association between purpose and cognitive functioning in MIDUS2 (Lewis et al., 2017). We build on these results here by investigating the relationship over time and by exploring the role of subjective memory beliefs. In the current study, we will refer to MIDUS2 and MIDUS3 as T1 and T2, respectively.

We included the data of 3633 participants—-2014 women and 1619 men — who completed the sense of purpose measure, the subjective memory measures, as well as the memory performance tests at T1. Mean age for this sample was $56.35(S D=12.28)$, with a range from 32-84 years at T1. Most of the sample was white (92.3\%), most were married (72.8\%), and most had at least a high school degree (93.1\%). For 2701 from the 3633 participants included, (at least partial) data was also available at T2 (74.3\%). Data on sense of purpose, subjective memory beliefs, and memory performance was available for 2397 (66\%), $2343(64.5 \%)$, and $2490(68.5 \%)$ participants, respectively.

\section{Measures}




\section{Sense of purpose in life}

Sense of purpose was assessed with the 7-item version of the Purpose in Life subscale from the Psychological Well-Being Scale (Ryff, 1989). The items (e.g., "I enjoy making plans for the future and working to make them a reality.") were scored on a scale from 1 (strongly disagree) to 7 (strongly agree). The mean scale score provided in the MIDUS data was used, which was calculated when at least half of the items were completed. Cronbach's alpha was .70 at $\mathrm{T} 1$ and .72 at $\mathrm{T} 2$.

\section{Memory performance}

Objective memory performance was assessed using the immediate and delayed word recall tasks from the Brief Test of Adult Cognition by Telephone (BTACT; Tun \& Lachman, 2006). For all analyses, the factor score was used based on the composite scores on the immediate and delayed word recall tasks. Reliability and validity of the BTACT in MIDUS has been previously demonstrated (Lachman, Agrigoroaei, Tun, \& Weaver, 2014).

\section{Subjective memory beliefs}

A composite measure for subjective memory beliefs was made from three items, assessing different aspects. The first was a single item tapping into general memory ability (“Compared to other people your age, how would you rate your memory?"), scored on a scale from 1 (Excellent) to 5 (Poor) (reverse-scored). To obtain a more stable measure, two additional items were selected from the Personality in Intellectual Aging Contexts Inventory, which focused more on subjective memory complaints (Lachman, Baltes, Nesselroade, \& Willis, 1982): “I don't remember things as well as I used to" and "There's not much I can do to keep my memory from going down hill”, scored on a scale from 1 (strongly agree) to 7 (strongly disagree). As described in the pre-registration document, these items were selected based on their face validity for the subjective memory construct. 
We performed a confirmatory factor analysis to test whether the three items could be appropriately combined to measure an underlying subjective memory beliefs construct. The three items loaded adequately on one underlying factor for both Time 1 (standardized loadings: $0.71,0.52$, and 0.62 ; proportion variance explained $=0.39$ ) and Time 2 (standardized loadings: $0.76,0.53$, and 0.59 ; proportion variance explained $=0.40$ ). Therefore, the single item was rescaled from a 1-5 scale to a 1-7 scale and a mean scale score of the three items was calculated. Cronbach's alpha was .60 at T1 and .62 at T2.

\section{Covariates}

In addition to age, gender, and education, we also included negative and positive affect, and self-rated health as covariates. Previous studies have demonstrated their potential relationships with our main outcome variables (e.g., Garcia, Al Nima, \& Kjell, 2014; Lee, 2016; Lewis et al., 2017). Participants rated their positive affect on 6 items (cheerful, in good spirits, extremely happy, calm and peaceful, satisfied, full of life) and negative affect on 6 items (sad, nervous, restless/fidgety, hopeless, everything an effort, worthless) during the past 30 days. Self-rated health was measured with 5 items on a 5-point scale.

\section{Analytic Plan}

Means, standard deviations, and correlations between the variables were calculated, and a MANOVA was performed to assess baseline differences between participants who dropped out after T1 and those who participated at both time points. To test our main hypotheses, cross-lagged panel analysis were performed in $\mathrm{R}$ using the lavaan package (Rosseel, 2012). We first tested two separate cross-lagged models: one with sense of purpose and memory performance and one with sense of purpose and subjective memory beliefs. In a third model, all three variables were combined to test a path model with simultaneous crosslagged paths between sense of purpose in life, subjective memory beliefs, and memory 
performance. In all models, age, gender, and education were entered as covariates at both T1 and T2. Self-rated health T1, positive affect T1, and negative affect T1 were added as covariates for $\mathrm{T} 1$; self-rated health $\mathrm{T} 2$, positive affect $\mathrm{T} 2$, and negative affect $\mathrm{T} 2$ were added as covariates for T2. ${ }^{1}$ Full information likelihood estimation (FIML) was used to handle missing data, with missing data assumed to be missing at random. To handle non-normality in the data, the robust MLR estimator was used (Rosseel, 2012). Standard fit indices were used to assess model fit: the $\chi^{2}$ Index should be as small as possible, the Comparative Fit Index (CFI) and Tucker-Lewis Index (TLI) should be larger than .90, and the Root Mean Square Error of Approximation (RMSEA) and Standardized Root Mean Square Residual (SRMR) should be smaller than .08 (Kline, 2005).

\section{Results}

\section{Preliminary analyses}

MANOVA analysis showed that participants who participated in both waves significantly differed at baseline from those who dropped out after T1 (Wilks' Lambda = $.920, F(7,3597)=44.84, p<.001)$. Participants who dropped out were significantly older $(M$ dropped-out $=59.73, S D=13.96)$ than those who $\operatorname{did} \operatorname{not}\left(M_{\text {longitudinal }}=55.10, S D=11.391, F(1\right.$, $3604)=100.43, p<.001)$, had higher negative affect $\left(M_{\text {dropped-out }}=1.59, S D=0.65\right.$ vs. $M$ longitudinal $=1.47, S D=0.53, F(1,3604)=30.04, p<.001)$ and lower positive affect $\left(M_{\text {dropped }}\right.$ out $=3.36, S D=0.73$ vs. $\left.M_{\text {longitudinal }}=3.45, S D=0.69, F(1,3604)=11.12, p=.001\right)$, lower self-rated health $\left(M_{\text {dropped-out }}=3.21, S D=1.10\right.$ vs. $M_{\text {longitudinal }}=3.69, S D=0.94, F(1,3604)=$ $163.72, p<.001)$, lower subjective memory belief ratings $\left(M_{\text {dropped-out }}=4.35, S D=1.34\right.$ vs. $\left.M_{\text {longitudinal }}=4.71, S D=1.28, F(1,3604)=50.55, p<.001\right)$, lower objective memory

\footnotetext{
${ }^{1}$ We also tested models where age, gender, and education were only added as covariates at $\mathrm{T} 2$, similar as one would in regression analyses. These models showed worse fit, although the primary conclusions with regard to our main hypotheses were not altered.
} 
performance scores $\left(M_{\text {dropped-out }}=-.28, S D=1.05\right.$ vs. $M_{\text {longitudinal }}=.12, S D=0.96, F(1,3604)$ $=111.29, p<.001)$, and finally lower sense of purpose $\left(M_{\text {dropped-out }}=5.25, S D=1.03 \mathrm{vs} . M\right.$ longitudinal $=5.60, S D=0.95, F(1,3604)=87.46, p<.001)$.

Table 1 shows the means, standard deviations and correlations of the study variables for both T1 and T2. At both time points, sense of purpose showed a moderate positive correlation with subjective memory and a small positive correlation with objective memory performance. At both time points, the correlation between subjective memory beliefs and memory performance was small (.15 and .22$)$, in line with previous meta-analyses.

\section{Cross-lagged analyses}

\section{Confirmatory cross-lagged analyses}

Results from the cross-lagged models are summarized in Table 2. Model 1 tested the cross-lagged relationships between sense of purpose and memory performance, and this model demonstrated good fit $\left[\chi^{2}(12)=68.956, p<0.001 ; \mathrm{CFI}=0.988 ; \mathrm{TLI}=0.958 ;\right.$ RMSEA $=.038 ; \mathrm{SRMR}=.015]$. The cross-lagged paths in this model were not significant, but the residual covariance between sense of purpose and memory performance at T2 was significant, indicating correlated change between the variables, although this correlation was very small ( $r$ $=.058, p=.005)$.

Model 2 tested the cross-lagged relationships between sense of purpose and subjective memory beliefs, and this model also demonstrated good fit $\left[\chi^{2}(12)=76.520, p<0.001 ; \mathrm{CFI}=\right.$ $0.985 ; \mathrm{TLI}=0.948 ; \mathrm{RMSEA}=.041 ; \mathrm{SRMR}=.017]$. In this model, sense of purpose at T1 significantly predicted subjective memory beliefs at $\mathrm{T} 2(\beta=0.050, p=.012)$. The residual covariance between sense of purpose and subjective memory beliefs was also significant $(r=$ $.149, p<.001)$. 
Model 3 tested the cross-lagged relationships between sense of purpose, memory performance, and subjective memory beliefs simultaneously, and it also demonstrated good fit $\left[\chi^{2}(18)=88.786, p<0.001 ; \mathrm{CFI}=0.989 ; \mathrm{TLI}=0.958 ; \mathrm{RMSEA}=.034 ; \mathrm{SRMR}=.016\right]$. Three cross-lagged paths were significant: sense of purpose at T1 again significantly predicted subjective memory beliefs at T2 $(\beta=0.049, p=.017)$. Furthermore, objective memory performance positively predicted subjective memory beliefs $(\beta=0.042, p=.023)$, and subjective memory beliefs in turn positively predicted memory performance $(\beta=0.037, p$ $=.029)$. All residual covariances were significant, indicating correlated changes between all three constructs. An overview of this main model is shown in Figure 1.

\section{Exploratory cross-lagged analyses}

We tested two additional models as an exploration of the role of the covariates included in models 1-3. We first tested the same model as Model 3 but without positive and negative affect as covariates. In this model (Model 4), one additional significant path emerged, from subjective memory beliefs $\mathrm{T} 1$ to sense of purpose $\mathrm{T} 2(\beta=0.056, p=.001)$. We then tested a model where self-rated health was also removed as a covariate. In this model (Model 5), an additional cross-lagged path emerged from sense of purpose T1 to memory performance $\mathrm{T} 2(\beta=0.040, p=.020)$.

\section{Discussion}

There is growing support for the idea that having a sense of purpose in life is a psychological strength related to many desired outcomes (Irving et al., 2017). One important outcome, especially for aging adults, is memory functioning. While previous studies have demonstrated an association between sense of purpose and memory, uncertainty remains about the direction of this relationship. Furthermore, studies up to now have failed to take into 
account the possible role that subjective beliefs about one's own memory functioning may play, above and beyond objective memory performance.

In this study, we used a large sample from the second and third waves of the MIDUS study to investigate the relationships between sense of purpose, memory performance, and subjective memory beliefs in middle and later adulthood over time. First, with regard to memory performance, there were no significant cross-lagged paths with sense of purpose, which was against our hypotheses. However, sense of purpose and objective memory performance were correlated within time at both $\mathrm{T} 1$ and $\mathrm{T} 2$, the latter reflecting correlated change of the variables. In other words, adults who have a relatively stronger decrease in sense of purpose will on average also show a stronger decrease in memory performance, and vice versa, although it should be noted that this correlation was very small. Second, with regard to memory beliefs, we found that sense of purpose positively predicted subjective memory beliefs over time, even after controlling for age, gender, education, positive and negative affect, and self-rated health. Again, it is important to note that while our findings further substantiate the claim that sense of purpose positively predicts important late life outcomes, the effect size was small. Within time correlations at both time points were also found between subjective memory beliefs and sense of purpose. Finally, memory performance and subjective memory beliefs positively predicted each other over time. So although the correlation between objective and subjective memory was small, as in previous studies (e.g., Beaudoin \& Desrichard, 2011), we replicate past findings that suggest the relationship persists over time (Hülür et al., 2015; Jorm et al., 2001).

Taken together, our findings provide further evidence for the positive relationship between sense of purpose and memory, both objective and subjective. Given that sense of purpose is regarded as a core aspect of psychological well-being (Ryff, 2013) and that (at least basic) cognitive skills are regarded as an important component of mental health 
(Galderisi, Heinz, Kastrup, Beezhold, \& Sartorius, 2015), these findings align with the idea that memory and purpose in life are important aspects of positive aging that are related to each other and co-develop over time.

From a critical perspective, it could be argued that relations between subjective memory scores and psychological well-being measures are partially the result of common method bias, for example, because of a generally more optimistic or pessimistic response tendency (Podsakoff, MacKenzie, \& Podsakoff, 2012). However, the fact that the association remains after controlling for positive affect provides a strong counterargument. Therefore, while some method bias may influence the magnitude of the association, linking sense of purpose to subjective memory beliefs over time provides valuable insight into the potential benefits of purposeful living in middle-to-older adulthood. Our results also add to evidence showing that indicators of objective and subjective memory may have different predictors and that both are important for understanding age-related cognitive changes.

One next step for research is to understand how these effects play out in daily life in order to explain the benefits of purpose for healthy cognitive aging. For instance, it has been suggested that one reason why purposeful adults appear to maintain better memory functioning is that they are more active and engaged with daily life (Lewis et al., 2017). Subjective memory beliefs likely play a role in this pathway insofar that older adults may be more likely to engage in daily activities because they are less concerned about the potential cognitive demands (Payne \& Lohani, 2020). If so, sense of purpose may lead to greater intellectual activity engagement because of the fact that purposeful adults hold more positive memory beliefs, or it may be that greater life engagement leads individuals to a more positive perception of their memory capabilities. Given that both beliefs and intellectual engagement may promote later memory functioning, work is needed to understand how sense of purpose influences both factors in daily cognitive life. 
In addition to these primary findings, we tested two exploratory models to further explore the role of the covariates included. First, when positive and negative affect were removed from the analyses, an additional path emerged from subjective memory beliefs to later sense of purpose. In other words, the relationship between sense of purpose and subjective memory beliefs became bi-directional. Second, when self-rated health was also removed from the analyses, an additional path emerged from sense of purpose to later memory performance. While these exploratory results should be interpreted with caution, they suggest that predictive effects from subjective memory on later sense of purpose or from sense of purpose to later objective memory performance may be dependent on whether affect and health are included in the models. However, it is not clear from the current analyses whether affect and self-rated health are mediating mechanisms between the memory-purpose association or confounding variables. These potential pathways therefore need formal testing in future studies with more measurement occasions.

\section{Limitations and future directions}

The present study is not without limitations. First, we were only able to test our model over two time points because the cognitive battery was only included starting in MIDUS2. Therefore, we unfortunately were unable to fully examine any mediational pathways and explanations underlying the relationship between sense of purpose and objective and subjective memory. Furthermore, the cross-lagged paths in two-wave data are known to be less stable, and we would recommend caution in interpreting these findings without replication in data with additional assessments (Newsom, 2013). Second, the findings need replication in more culturally diverse samples, as most studies up to now have been undertaken primarily in Western populations. Third, because of the restrictions of working with an existing dataset, we used a self-constructed measure of subjective memory beliefs, with items referring to different aspects of the concept. The use of a multi-item measure 
tapping into different facets (general ability, memory problems) of a broader memory selfconcept can be seen as an asset, but the items included in the current study were not formulated specifically with this goal in mind. Although the measure showed acceptable internal consistency, future work is needed using a longer, validated instrument with multiple items assessing the different components.

\section{Conclusion}

By showing that sense of purpose positively predicts subjective memory beliefs over time and that changes in sense of purpose are positively related to changes in both objective and subjective memory, our study adds evidence to a growing body of work identifying sense of purpose as a key concept for positive adult aging. Although continued efforts are needed to uncover the complex mechanisms underlying the associations between sense of purpose and memory, sense of purpose may be a key target for future intervention, as it is positively linked to both performance-based and subjective cognitive outcomes. Preliminary work suggests the feasibility and usefulness of purpose interventions (e.g., Friedman et al., 2017), but more work is needed to further develop and implement interventions that can enhance sense of purpose in adults transitioning to older age, especially for those facing cognitive challenges. 


\section{References}

Allerhand, M., Gale, C. R., \& Deary, I. J. (2014). The dynamic relationship between cognitive function and positive well-being in older people: A prospective study using the English Longitudinal Study of Aging. Psychology and Aging, 29(2), 306.

Beaudoin, M., \& Desrichard, O. (2011). Are memory self-efficacy and memory performance related? A meta-analysis. Psychological Bulletin, 137(2), 211. doi:10.1037/a0022106

Boyle, P. A., Buchman, A. S., Barnes, L. L., \& Bennett, D. A. (2010). Effect of a purpose in life on risk of incident Alzheimer disease and mild cognitive impairment in community-dwelling older persons. Archives of General Psychiatry, 67(3), 304. doi:10.1001/archgenpsychiatry.2009.208

Boyle, P. A., Buchman, A. S., Wilson, R. S., Lei, Y., Schneider, J. A., \& Bennett, D. A. (2012). Effect of purpose in life on the relation between alzheimer disease pathologic changes on cognitive function in advanced age. Archives of General Psychiatry, 69(5), 499. doi:10.1001/archgenpsychiatry.2009.208

Brim, O. G., Ryff, C. D., \& Kessler, R. C. (2004). How healthy are we? A national study of well-being at midlife. Chicago, IL: University of Chicago Press.

Buckley, R., Saling, M. M., Ames, D., Rowe, C. C., Lautenschlager, N. T., Macaulay, S. L., . .. Savage, G. (2013). Factors affecting subjective memory complaints in the AIBL aging study: biomarkers, memory, affect, and age. International psychogeriatrics, 25(8), 1307-1315. doi:10.1017/S1041610213000665

Burmester, B., Leathem, J., \& Merrick, P. (2016). Subjective cognitive complaints and objective cognitive function in aging: a systematic review and meta-analysis of recent cross-sectional findings. Neuropsychology Review, 26(4), 376-393.

doi:10.1007/s11065-016-9332-2 
Cotton Bronk, K., Hill, P. L., Lapsley, D. K., Talib, T. L., \& Finch, H. (2009). Purpose, hope, and life satisfaction in three age groups. The Journal of Positive Psychology, 4(6), 500-510. doi:10.1080/17439760903271439

Crumley, J. J., Stetler, C. A., \& Horhota, M. (2014). Examining the relationship between subjective and objective memory performance in older adults: A meta-analysis. Psychology and Aging, 29(2), 250. doi:10.1037/a0035908

Cutler, S. J., \& Brăgaru, C. (2016). Do worries about cognitive functioning and concerns about developing Alzheimer's disease affect psychological well-Being? Journal of aging and health, 29(8), 1271-1287. doi:10.1177/0898264316674535

DeWitz, S. J., Woolsey, M. L., \& Walsh, W. B. (2009). College student retention: An exploration of the relationship between self-efficacy beliefs and purpose in life among college students. Journal of college student development, 50(1), 19-34. doi:10.1353/csd.0.0049

Friedman, E. M., Ruini, C., Foy, R., Jaros, L., Sampson, H., \& Ryff, C. D. (2017). Lighten UP! A community-based group intervention to promote psychological well-being in older adults. Aging \& Mental Health, 21(2), 199-205. doi:10.1080/13607863.2015.1093605

Galderisi, S., Heinz, A., Kastrup, M., Beezhold, J., \& Sartorius, N. (2015). Toward a new definition of mental health. World psychiatry : official journal of the World Psychiatric Association (WPA), 14(2), 231-233. doi:10.1002/wps.20231

Garcia, D., Al Nima, A., \& Kjell, O. N. (2014). The affective profiles, psychological wellbeing, and harmony: environmental mastery and self-acceptance predict the sense of a harmonious life. PeerJ, 2, e259. doi: 10.7717/peerj.259 
Gates, N., Valenzuela, M., Sachdev, P. S., \& Singh, M. A. F. (2014). Psychological wellbeing in individuals with mild cognitive impairment. Clinical interventions in Aging, 9, 779. doi:10.2147/CIA.S58866

Hill, P. L., Aschwanden, D., Payne, B. R., \& Allemand, M. (2020). Daily cognitive complaints and engagement in older adulthood: Personality traits are more predictive than cognitive performance. Psychology and Aging.

Hughes, M. L., Agrigoroaei, S., Jeon, M., Bruzzese, M., \& Lachman, M. E. (2018). Change in cognitive performance from midlife into old age: Findings from the Midlife in the United States (MIDUS) study. Journal of the International Neuropsychological Society, 24(8), 805-820. doi:10.1017/S1355617718000425

Hülür, G., Hertzog, C., Pearman, A. M., \& Gerstorf, D. (2015). Correlates and Moderators of Change in Subjective Memory and Memory Performance: Findings from the Health and Retirement Study. Gerontology, 61(3), 232-240. doi:10.1159/000369010

Hurt, C. S., Burns, A., \& Barrowclough, C. (2011). Perceptions of memory problems are more important in predicting distress in older adults with subjective memory complaints than coping strategies. International psychogeriatrics, 23(8), 1334-1343. doi:10.1017/S104161021100038X

Irving, J., Davis, S., \& Collier, A. (2017). Aging with purpose: Systematic search and review of literature pertaining to older adults and purpose. The International Journal of Aging and Human Development, 85(4), 403-437. doi:10.1177/0091415017702908

Jorm, A. F., Christensen, H., Korten, A., Jacomb, P., \& Henderson, A. S. (2001). Memory complaints as a precursor of memory impairment in older people: a longitudinal analysis over 7-8 years. Psychological medicine, 31(3), 441-449.

doi:10.1017/S0033291701003245P 
Kim, G., Shin, S. H., Scicolone, M. A., \& Parmelee, P. (2019). Purpose in Life Protects Against Cognitive Decline Among Older Adults. The American Journal of Geriatric Psychiatry, 27(6), 593-601. doi:10.1016/j.jagp.2019.01.010

Kline, R. B. (2005). Principles and practice of structural equation modeling (2nd ed.). New York, NY: The Guilford Press.

Lachman, M. E., Agrigoroaei, S., Tun, P. A., \& Weaver, S. L. (2014). Monitoring cognitive functioning: Psychometric properties of the Brief Test of Adult Cognition by Telephone. Assessment, 21(4), 404-417. doi:10.1177/1073191113508807

Le Carret, N., Lafont, S., Letenneur, L., Dartigues, J.-F., Mayo, W., \& Fabrigoule, C. (2003). The effect of education on cognitive performances and its implication for the constitution of the cognitive reserve. Developmental neuropsychology, 23(3), 317-337. doi:10.1207/S15326942DN2303_1

Lee, P.-L. (2016). A joyful heart is good medicine: Positive affect predicts memory complaints. The American Journal of Geriatric Psychiatry, 24(8), 662-670. doi:10.1016/j.jagp.2016.04.001

Lewis, N. A., Turiano, N. A., Payne, B. R., \& Hill, P. L. (2017). Purpose in life and cognitive functioning in adulthood. Aging, Neuropsychology, and Cognition, 24(6), 662-671. doi:10.1080/13825585.2016.1251549

Luck, T., Roehr, S., Rodriguez, F. S., Schroeter, M. L., Witte, A. V., Hinz, A., . . RiedelHeller, S. G. (2018). Memory-related subjective cognitive symptoms in the adult population: prevalence and associated factors - results of the LIFE-Adult-Study. BMC Psychology, 6(1), 23. doi:10.1186/s40359-018-0236-1

McKnight, P. E., \& Kashdan, T. B. (2009). Purpose in life as a system that creates and sustains health and well-Being: An integrative, testable theory. Review of General Psychology, 13(3), 242-251. doi:10.1037/a0017152 
Mendonça, M. D., Alves, L., \& Bugalho, P. (2016). From subjective cognitive complaints to dementia: who is at risk?: a systematic review. American Journal of Alzheimer's Disease \& Other Dementias ${ }^{\circledR}, 31(2), 105-114$. doi:10.1177/1533317515592331

Nebes, R. D., Buysse, D. J., Halligan, E. M., Houck, P. R., \& Monk, T. H. (2009). Selfreported sleep quality predicts poor cognitive performance in healthy older adults. The Journals of Gerontology: Series B, 64(2), 180-187. doi:10.1093/geronb/gbn037

Newsom, J. T. (2013). Basic longitudinal analysis approaches for continuous and categorical variables. In J. T. Newsom, R. N. Jones, \& S. M. Hofer (Eds.), Longitudinal data analysis: A practical guide for researchers in aging, health, and social science (Vol. 18, pp. 143-179). New York, NY: Routledge.

Nyström, M. B., Sörman, D. E., Kormi-Nouri, R., \& Rönnlund, M. (2019). To what extent is subjective well-being in late adulthood related to subjective and objective memory functioning? Five-year cross-lagged panel analyses. Aging \& Mental Health, 23(1), 92-99.

Ong, A. D., \& Patterson, A. (2016). Eudaimonia, aging, and health: a review of underlying mechanisms. In J. Vittersø (Ed.), Handbook of Eudaimonic Well-Being. International Handbooks of Quality-of-Life (pp. 371-378). Cham: Springer.

Payne, B. R., Gross, A. L., Hill, P. L., Parisi, J. M., Rebok, G. W., \& Stine-Morrow, E. A. L. (2017). Decomposing the relationship between cognitive functioning and self-referent memory beliefs in older adulthood: what's memory got to do with it? Aging, Neuropsychology, and Cognition, 24(4), 345-362. doi:10.1080/13825585.2016.1218425

Payne, B. R., \& Lohani, M. (2020). Personality and cognitive health in aging. In P. L. A. Hill, M. (Ed.), New Directions in Personality and Aging: Springer. 
Pinquart, M. (2002). Creating and maintaining purpose in life in old age: A meta-analysis. Ageing international, 27(2), 90-114. doi:10.1007/s12126-002-1004-2

Podsakoff, P. M., MacKenzie, S. B., \& Podsakoff, N. P. (2012). Sources of method bias in social science research and recommendations on how to control it. Annual Review of Psychology, 63, 539-569. doi:10.1146/annurev-psych-120710-100452

Radler, B. T., \& Ryff, C. D. (2010). Who participates? Accounting for longitudinal retention in the MIDUS national study of health and well-being. Journal of aging and health, 22(3), 307-331. doi:10.1177/0898264309358617

Rosseel, Y. (2012). Lavaan: An R package for structural equation modeling and more. Version 0.5-12 (BETA). Journal of statistical software, 48(2), 1-36. doi:10.18637/jss.v048.i02

Rowell, S. F., Green, J. S., Teachman, B. A., \& Salthouse, T. A. (2016). Age does not matter: Memory complaints are related to negative affect throughout adulthood. Aging \& Mental Health, 20(12), 1255-1263. doi:10.1080/13607863.2015.1078284

Ryff, C. D. (1989). Happiness is everything, or is it? Explorations on the meaning of psychological well-being. Journal of Personality and Social Psychology, 57(6), 1069. doi:10.1037/0022-3514.57.6.1069

Ryff, C. D. (2013). Psychological well-being revisited: Advances in the science and practice of eudaimonia. Psychotherapy and Psychosomatics, 83(1), 10-28. doi:10.1159/000353263

Salthouse, T. A. (2006). Mental exercise and mental aging: Evaluating the validity of the "use it or lose it" hypothesis. Perspectives on Psychological Science, 1(1), 68-87. doi:10.1111/j.1745-6916.2006.00005.x 
Scheier, M. F., Wrosch, C., Baum, A., Cohen, S., Martire, L. M., Matthews, K. A., . . Zdaniuk, B. (2006). The life engagement test: Assessing purpose in life. Journal of Behavioral Medicine, 29(3), 291. doi:10.1007/s10865-005-9044-1

Slavin, M. J., Brodaty, H., Kochan, N. A., Crawford, J. D., Trollor, J. N., Draper, B., \& Sachdev, P. S. (2010). Prevalence and predictors of "subjective cognitive complaints" in the Sydney Memory and Ageing Study. The American Journal of Geriatric Psychiatry, 18(8), 701-710. doi:10.1097/JGP.0b013e3181df49fb

Snitz, B. E., Small, B. J., Wang, T., Chang, C.-C. H., Hughes, T. F., \& Ganguli, M. (2015). Do subjective memory complaints lead or follow objective cognitive change? A fiveyear population study of temporal influence. Journal of the International Neuropsychological Society, 21(9), 732-742. doi:10.1017/S1355617715000922

Sofi, F., Valecchi, D., Bacci, D., Abbate, R., Gensini, G., Casini, A., \& Macchi, C. (2011). Physical activity and risk of cognitive decline: a meta-analysis of prospective studies. Journal of internal medicine, 269(1), 107-117. doi:10.1111/j.1365-2796.2010.02281.x

Steinberg, S. I., Negash, S., Sammel, M. D., Bogner, H., Harel, B. T., Livney, M. G., . . Arnold, S. E. (2013). Subjective memory complaints, cognitive performance, and psychological factors in healthy older adults. American Journal of Alzheimer's Disease \& Other Dementias ${ }^{\circledR}, 28(8), 776-783$. doi:10.1177/1533317513504817

Steptoe, A. (2019). Happiness and health. Annual review of public health, 40, 339-359. doi:10.1146/annurev-publhealth-040218-044150

Strout, K. A., \& Howard, E. P. (2012). The six dimensions of wellness and cognition in aging adults. Journal of Holistic Nursing, 30(3), 195-204. doi:10.1177/0898010112440883

Tun, P. A., \& Lachman, M. E. (2006). Telephone assessment of cognitive function in adulthood: the Brief Test of Adult Cognition by Telephone. Age and ageing, 35(6), 629-632. doi:10.1093/ageing/af1095 
Wilson, R. S., Boyle, P. A., Segawa, E., Yu, L., Begeny, C. T., Anagnos, S. E., \& Bennett, D. A. (2013). The influence of cognitive decline on well-being in old age. Psychology and Aging, 28(2), 304.

Windsor, T. D., Curtis, R. G., \& Luszcz, M. A. (2015). Sense of purpose as a psychological resource for aging well. Developmental psychology, 51(7), 975.

doi:10.1037/dev0000023 
Table 1

Means, standard deviations, and bivariate Pearson correlations with confidence intervals of main study variables at T1 and T2

\begin{tabular}{|c|c|c|c|c|c|c|c|c|c|c|}
\hline Variable & $M$ & $S D$ & 1 & 2 & 3 & 4 & 5 & 6 & 7 & 8 \\
\hline 2. education & 7.28 & 2.54 & $\begin{array}{l}-.15^{* *} \\
{[-.18,-.12]}\end{array}$ & & & & & & & \\
\hline 3. negative affect $\mathrm{T} 1$ & 1.50 & 0.57 & $\begin{array}{l}-.10 * * \\
{[-.14,-.07]}\end{array}$ & $\begin{array}{l}-.10^{* *} \\
{[-.14,-.07]}\end{array}$ & & & & & & \\
\hline 5. self-rated health $\mathrm{T} 1$ & 3.57 & 1.00 & $\begin{array}{l}-.16^{* *} \\
{[-.19,-.13]}\end{array}$ & $\begin{array}{c}.26^{* *} \\
{[.23, .29]}\end{array}$ & $\begin{array}{l}-.33^{* *} \\
{[-.36,-.30]}\end{array}$ & $\begin{array}{l}.30^{* *} \\
{[.27, .33]}\end{array}$ & & & & \\
\hline 6. purpose in life $\mathrm{T} 1$ & 5.51 & 0.98 & $\begin{array}{l}-.07 * * \\
{[-.10,-.03]}\end{array}$ & $\begin{array}{l}.19^{* *} \\
{[.16, .22]}\end{array}$ & $\begin{array}{l}-.43^{* *} \\
{[-.46,-.41]}\end{array}$ & $\begin{array}{l}.45^{* *} \\
{[.42, .48]}\end{array}$ & $\begin{array}{l}.29^{* *} \\
{[.26, .32]}\end{array}$ & & & \\
\hline 9. negative affect $\mathrm{T} 2$ & 1.46 & 0.56 & $\begin{array}{l}-.07 * * \\
{[-.11,-.03]}\end{array}$ & $\begin{array}{l}-.11 * * \\
{[-.15,-.07]}\end{array}$ & $\begin{array}{l}.56^{* *} \\
{[.54, .59]}\end{array}$ & $\begin{array}{l}-.39 * * \\
{[-.42,-.35]}\end{array}$ & $\begin{array}{l}-.27 * * \\
{[-.30,-.23]}\end{array}$ & $\begin{array}{l}-.33^{* *} \\
{[-.37,-.30]}\end{array}$ & $\begin{array}{l}-.26^{* *} \\
{[-.30,-.23]}\end{array}$ & $\begin{array}{l}-.05 * * \\
{[-.09,-.01]}\end{array}$ \\
\hline 10. positive affect $\mathrm{T} 2$ & 3.45 & 0.71 & $\begin{array}{l}.12 * * \\
{[.08, .16]}\end{array}$ & $\begin{array}{c}.01 \\
{[-.03, .05]}\end{array}$ & $\begin{array}{l}-.43 * * \\
{[-.46,-.40]}\end{array}$ & $\begin{array}{l}.59 * * \\
{[.56, .61]}\end{array}$ & $\begin{array}{c}.25 * * \\
{[.22, .29]}\end{array}$ & $\begin{array}{l}.37 * * \\
{[.33, .40]}\end{array}$ & $\begin{array}{c}.23 * * \\
{[.20, .27]}\end{array}$ & $\begin{array}{c}.01 \\
{[-.03, .05]}\end{array}$ \\
\hline
\end{tabular}




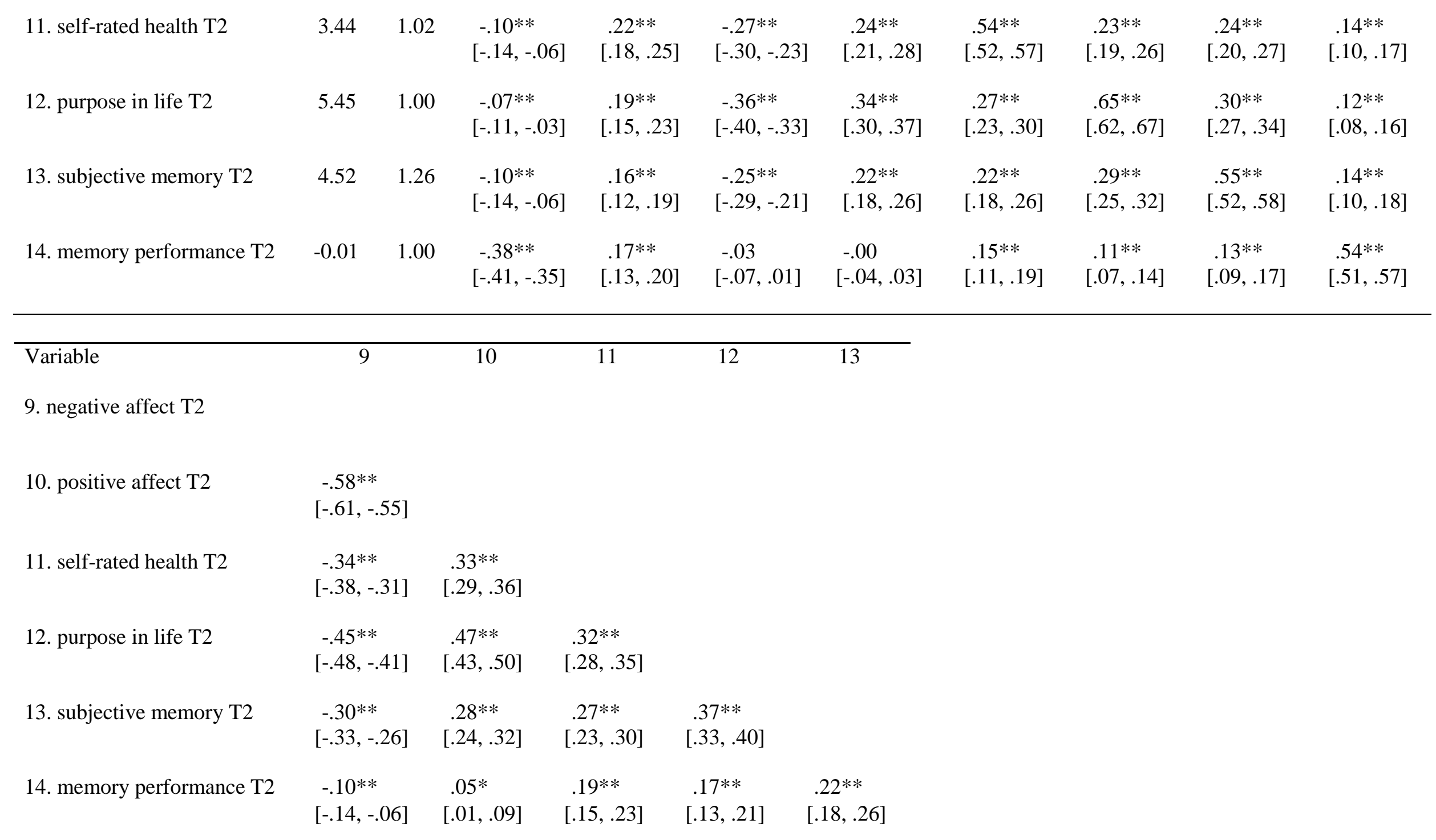

Note. $M=$ mean, $S D=$ standard deviation. The mean education (7.28) corresponds to 3 or more years of college education. Values in square brackets indicate the $95 \%$ confidence interval for each correlation. $* * p<.01,{ }^{*} p<.05$. 
Table 2

Summary of cross-lagged models 1 to 5

\begin{tabular}{|c|c|c|c|c|c|c|c|c|c|c|c|c|c|c|c|}
\hline \multirow[t]{2}{*}{ Effect } & \multicolumn{3}{|c|}{ Model 1} & \multicolumn{3}{|c|}{ Model 2} & \multicolumn{3}{|c|}{ Model 3} & \multicolumn{3}{|c|}{ Model 4} & \multicolumn{3}{|c|}{ Model 5} \\
\hline & $\begin{array}{r}\text { Stand. } \\
\text { estimate }\end{array}$ & S.E. & $p$ & $\begin{array}{r}\text { Stand. } \\
\text { estimate }\end{array}$ & S.E. & $p$ & $\begin{array}{r}\text { Stand. } \\
\text { estimate }\end{array}$ & S.E. & $p$ & $\begin{array}{r}\text { Stand. } \\
\text { estimate }\end{array}$ & S.E. & $p$ & $\begin{array}{r}\text { Stand. } \\
\text { estimate }\end{array}$ & S.E. & $p$ \\
\hline \multicolumn{16}{|l|}{ Autoregressive effects } \\
\hline Sense of Purpose T1-T2 & .514 & .018 & $<.001$ & .509 & .018 & $<.001$ & .508 & .018 & $<.001$ & .593 & .018 & $<.001$ & .612 & .018 & $<.001$ \\
\hline Memory performance $\mathrm{T} 1-\mathrm{T} 2$ & .413 & .020 & $<.001$ & - & - & - & .411 & .020 & $<.001$ & .412 & .020 & $<.001$ & .419 & .020 & $<.001$ \\
\hline Subjective memory T1-T2 & - & - & - & .471 & .019 & $<.001$ & .468 & .019 & $<.001$ & .487 & .019 & $<.001$ & .504 & .019 & $<.001$ \\
\hline \multicolumn{16}{|l|}{ Cross-lagged effects } \\
\hline $\begin{array}{l}\text { Sense of purpose } \mathrm{T} 1 \rightarrow \\
\text { Memory performance } \mathrm{T} 2\end{array}$ & .023 & .003 & .205 & - & - & - & .013 & .003 & .465 & .029 & .003 & .098 & .040 & .003 & .020 \\
\hline $\begin{array}{l}\text { Memory performance } \mathrm{T} 1 \rightarrow \\
\text { Sense of Purpose T2 }\end{array}$ & .015 & .111 & .348 & - & - & - & .013 & .112 & .396 & .014 & .119 & .419 & .024 & .122 & .158 \\
\hline $\begin{array}{l}\text { Sense of Purpose T1 } \rightarrow \\
\text { Subjective memory T2 }\end{array}$ & - & - & - & .050 & .004 & .012 & .048 & .004 & .017 & .094 & .004 & $<.001$ & 109 & .003 & $<.001$ \\
\hline $\begin{array}{l}\text { Subjective memory T1 } \rightarrow \\
\text { Sense of Purpose T2 }\end{array}$ & - & - & - & .024 & .088 & .140 & .023 & .088 & .154 & .056 & .094 & .001 & .082 & .095 & $<.001$ \\
\hline $\begin{array}{l}\text { Memory performance } \mathrm{T} 1 \rightarrow \\
\text { Subjective memory } \mathrm{T} 2\end{array}$ & - & - & - & - & - & - & .042 & .023 & .023 & .042 & .023 & .023 & .049 & .024 & .008 \\
\hline $\begin{array}{l}\text { Subjective memory } \mathrm{T} 1 \mathrm{\rightarrow} \\
\text { Memory performance } \mathrm{T} 2\end{array}$ & - & - & - & - & - & - & .037 & .013 & .029 & .044 & .013 & .009 & .058 & .013 & .001 \\
\hline
\end{tabular}




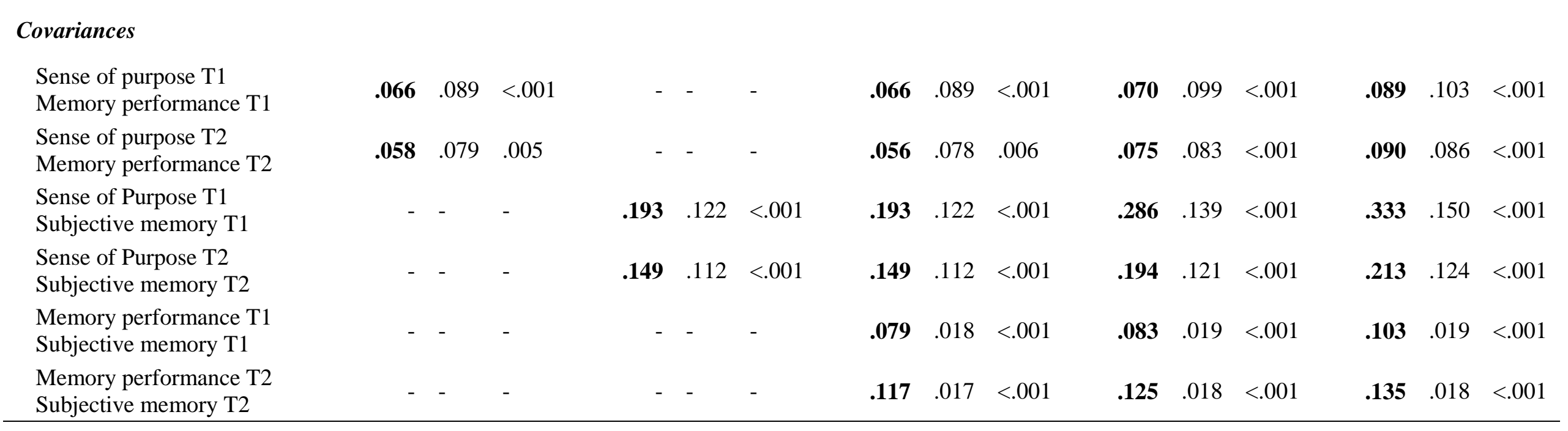

Note. $n=3633$. Covariances at T2 reflect residual covariances. Model 3 includes the effects of all covariates at both time points (age, sex, education, positive and negative affect, self-rated health). Model 4 includes all covariates except positive and negative affect. Model 5 includes all covariates except positive and negative affect and self-rated health. Estimates in bold are significant at least at the .05 level. Stand. $=$ standardized, S.E. $=$ standard error. 


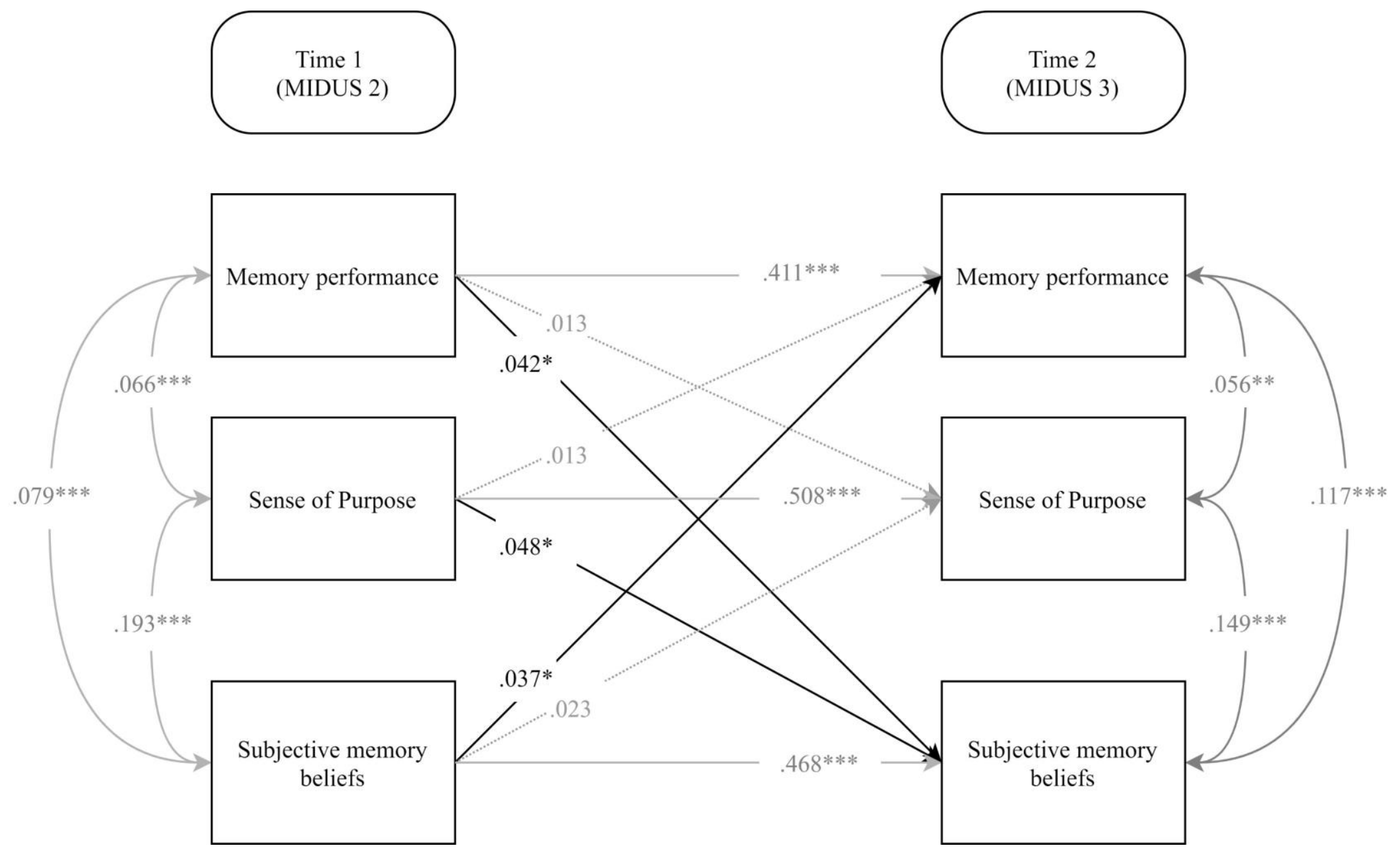

Figure 1. Summary of Model $3(n=3633)$. Covariate effects (age, sex, education, positive and negative affect, self-rated health) are not shown for clarity. Double arrows represent covariances.

$* * * p<.001 ; * * p<.01 ; * p<.05$. 